\title{
The Peer Assisted Teaching Model for Undergraduate Research at a HBCU
}

\author{
Liyun $\mathrm{Wu}^{1} \&$ Marilyn W. Lewis ${ }^{1}$ \\ ${ }^{1}$ School of Social Work, Norfolk State University, USA \\ Correspondence: Liyun Wu, School of Social Work, Norfolk State University, Norfolk, Virginia, USA. Tel: \\ 1-757-823-9037. E-mail: lwu@nsu.edu
}

Received: October 26, 2017

Accepted: November 22, 2017 Online Published: December 21, 2017

doi:10.5539/jel.v7n2p50

URL: http://doi.org/10.5539/jel.v7n2p50

\begin{abstract}
Despite wide application of research skills in higher education, undergraduate students reported research and computer anxiety, and low association between research and their professional goals. This study aims to assess whether peer-assisted mentoring programs would promote positive changes in undergraduates' attitudes toward research. Using a quasi-experimental one-group, pretest-posttest research design, the study assessed changes in attitudes by having doctoral candidates mentor undergraduate students during a summer statistics camp. Findings from paired-samples t-test indicated that students became familiar with the twelve statistical concepts upon completion, gained more positive affect related to statistics and an increase in their positive attitude about statistical skills, whereas they had lower scores prior to it. Notwithstanding the small sample size, these data indicate that including a peer assisted statistics camp in the academic curriculum would be beneficial for undergraduate students and increase their knowledge about research and statistics.
\end{abstract}

Keywords: undergraduate education, research methods, peer-assisted, teaching, mentoring, social work, HBCU

\section{Introduction}

\subsection{Introduce the Problem}

There has been a rapid increase in application of technological advances among social work researchers. These advances are increasingly essential to the undergraduate curriculum for the Baccalaureate in Social Work (BSW). BSW students are expected to become familiar with statistical software, conduct data analysis by applying statistical methods, develop proficiency in word processing programs, and create "PowerPoint" presentations. Despite this wide application of technological methods in BSW education, social work students reported more research and computer anxiety than their counterparts in psychology and business in a comparative study (Davis, 2003; Green, Bretzin, Leininger, \& Stauffer, 2001; Maschi, Wells, Slater, MacMillan, \& Ristow, 2013). Even though BSW students are typically at ease when expected to learn clinical information directly related to general practice with individuals, families, groups, and communities, they are less likely to associate learning research methods with their professional social work goals (Harder, 2010; Hudson, 1978a). Research methods courses are required by Council of Social Work Education (CSWE) to be included in the social work curriculum, thus inability to pass the research courses results in failure to graduate from an accredited program. To reduce student apprehension and increase proficiency in these required courses, educators must apply novel strategies to engage students and increase retention and graduation (Einbinder, 2014; Harder, 2010).

Infusion of research into social work education has been a major goal of the National Association of Social Work (NASW) and the Council on Social Work Education because it is essential for continued growth and improvement of social work profession. As stated in the NASW bylaws, one of the three major purposes of social work is “...utilization of the professional knowledge and skills of social work and to expand through research, the knowledge necessary to define and attain these goals" (NASW, 2012). Similarly, the CSWE Core Competencies address the importance of research several times, such as in "educational policy 2.1.6: ... use practice experience to inform research, employ evidence-based interventions, evaluate their own practice, and use research findings to improve practice, policy, and social service delivery... and understand scientific and ethical approaches to building knowledge" (CSWE, 2012). 
Despite the profession's mandate that social workers embrace research, social work students have indicated low levels of interest in use of technology and data analysis inherent in research and higher levels of anxiety, compared to students majored in psychology and business (Bolin, GlenMaye, Lee, \& Yoon, 2012; Green, Bretzin, Leininger, \& Stauffer, 2001; Peterson, Bacon, Phillips, \& Machunda, 2011; Royse \& Rompf, 1992). Some educators explain this disparity by suggesting that social work students' poor statistical performance may be caused by faculty characteristics or pedagogy (Faver, Fox, Hunter, \& Shannon, 1986; Hudson, 1978b; Pan \& Tang, 2005; Unrah \& Beck, 2004). Others argue that low levels of research success is related to high levels of anxiety (Royse \& Rompf, 1992) that reflects the profession's deep-rooted climate of resistance to a science, technology, engineering, mathematics (STEM) curriculum, within which research methods is embedded and changing this climate would require an institutional-level response (Adam, Zosky, \& Unrau, 2004; Pan \& Tang, 2005). Indeed, in 1968 the schools of social work credentialing body CSWE (1971) eliminated the academic requirement that MSW students must complete either a group research project or a master thesis. According to Dulmas \& Sowers (2012), their thinking was that this curriculum change would force schools to develop innovative research courses.

Science, engineer, technology, and mathematics training in health care settings (STEM-H) is germane to BSW prepared social workers practicing in a variety of settings. In order to practice successfully, each must be able to understand and communicate with medical personnel, including nurses, doctors, and a number of technicians. Hudson had promoted incorporating a scientific foundation to the profession of social work for many years. In a seminal paper, Hudson (1978a) stated that if social workers "cannot measure the client's problem, it does not exist... (and) you cannot treat it." Hudson (1978b) went on to argue that social work students don't embrace empirical research because they were not taught its relevance to their practice goals. Kirk, Osmalov, \& Fischer (1976) found that while social workers stated research was useful to direct practitioners, they did not use it in the daily clinical practice. This appears to occur even though it has been established that single-subject research design is applicable to social work practice (DiNoia \& Tripodi, 2008; Tripodi, 1994). In a generalist practice in a health care setting, BSW-prepared social workers can see that empirical research inform their practice.

According to Unrau \& Beck (2004), social work students' reluctance to embrace empirical research was related to a lack of confidence. They used a novel approach to engage them and increase their confidence so they could achieve mastery, but with disappointing results. Compared to students in a STEM-oriented Speech Pathology program, social work students reported fewer gains in confidence than their counterparts (Einbinder, 2014).

\subsection{Explore Importance of the Problem}

Overcoming resistance to STEM curriculum among bachelor level social work students at Historically Black Colleges and Universities (HBCUs) is critical for post-graduate economic success. While a minority segment of the U.S. population and most U.S. institutions of higher learning, African Americans are in the majority at HBCUs. Established during segregation, when Black students weren't allowed entry into Predominantly White Institutions (PWI), HBCUs have successfully trained generations of African American leaders in every sector of this country. Despite playing a critical role in the American system of higher education, today's HBCUs are challenged to effectively prepare BSW students to compete in the proliferation of baccalaureate programs training students to enter the highly competitive job market. This is necessary, according to Ladson-Billings \& Tate (1995) to balance racialized hiring practices. An introduction of STEM terminology and concepts learned in required research courses increases ability of new BSW graduates to compete in health care settings (e.g., physical rehabilitation centers, psychiatric hospitals, dialysis centers, HIV/AIDS clinic, alcohol and drug center) or as Piotrowski \& Hemasinha (2011) found, government, finance, and teaching. Bybee (2010) argues that STEM is not limited to math and science but also involves technology and engineering as tools to solving problems and new ways of problem solving.

This relevance is often overlooked. At a mid-size HBCU, Talley \& Scherer (2013) reported that many students expressed dislike for STEM courses even though those courses are critical to graduation. This alienation can be counteracted by the relationship of the student and professors and peers in STEM courses (Toldson, 2013). Toldson found that African American students who attended a HBCU reported that their professors were more sensitive to their cultural background compared to their counterparts who attended a PWI, or other predominantly minority-serving institutions and they were most likely to feel support from their peers in STEM courses. This is critical to academic success as Appel, Kronberger, \& Aronson (2011) found that stereotyping of students based on gender impaired their scores on STEM-test preparation more than men's test scores. Pan and Tang (2005) found that instructors' attitudes have been found to be a significant factor in statistics-related anxiety and may explain why of the African American U.S. students graduating with STEM degrees, 40\% received their degrees from a HBCU. 
Compared to Caucasian students, female African American social work students scored higher on a scale of statistics anxiety (Davis, 2003), and a sample of predominantly female African American Department of Education students scored higher levels of statistics-related anxiety and test anxiety compared to their Caucasian counterparts (Onwuegbuzie, 1999). Among many factors, statistics-related anxiety has been identified as an obstacle to academic success among African American BSW students. A recent study had identified that African American students had lower nationwide college graduation rates $(42 \%)$, compared to their Caucasian counterparts $(62 \%)$. Educators from across the country have initiated new curricula to narrow this achievement gap. Goonatilake, Chappa, Bachnak, \& San Miguel (2010) developed a pre-freshman intensive mathematics camp for incoming minority college students. They found that students who participated in the one week mathematics camp were more likely to earn A's and B's in college math courses compared to incoming students who did not participate in the math camp. The students worked in teams and the ones who scored better on daily tests, taught the others. Their model is similar to "Peer-Led Team Learning" (Chesney, 2011) developed at the University of Texas at Dallas to engage students in learning and to increase success in STEM courses. Their rationale behind involving students to educate other students who were at risk for failing a course that was a prerequisite to other STEM courses was to decrease the feeling of intimidation experienced by the student-learner. This is important when teaching course material that provokes anxiety (Davis, 2003; Einbinder, 2014). A second benefit was to increase mastery of the subject by the students who acted as instructors. Chesney (2011) speculated that the success of the program was due to the leaders' guidance, instruction, encouragement, but also structured group learning and applied learning. Ginty \& Harding (2014) found that students-to-student learning resulted in an increased understanding of subject matter because the students perceived the learning process provided support and allowed more interaction between the learner and the mentor.

\subsection{State the Hypothesis}

A pilot project was developed to test a peer assisted research model that consolidates educational resources in a baccalaureate social work program at a HBCU. The aim was to determine whether a mentor-mentee partnership of doctoral candidates and BSW students would be associated with a positive change in the undergraduates' attitudes toward research and increase their applied research skills. We anticipated that the completion of the project would increase the undergraduate student's facility with research and play a constructive role in their progress toward degree completion. Unlike their peers at a large, research-intensive Research I university, doctoral students at small HBCUs do not have access to teaching assistantships typically offering free tuition and stipends. Developing short-term teaching assistantship opportunities for $\mathrm{PhD}$ students provides practical, on-the-job skills, develops classroom leadership skills, and reinforces their research knowledge base.

The research question was whether a faculty-led, peer-assisted, and non-credited mentoring program would improve students' attitudes about research over and above their attitude after taking an introductory research course. It was hypothesized that one-to-one mentoring obtained through regular meetings with faculty-trained PhD student mentors would improve undergraduates' attitudes and enhance their research skills.

\section{Method}

This pilot study implemented a quasi-experimental, one-group, pretest- posttest research design with non-random convenience sampling to assess BSW students' attitudes toward research at an HBCU. Six attitude domains, including affect, cognitive competence, value, difficulty, interest and efforts were measured using the Survey of Attitudes toward Statistics (SATS-36) instrument (Schau, 2003). The university's Institutional Review Board (IRB) granted expedited approval for this study. The questionnaire package consisted of an informed consent form, a survey of demographic characteristics and their knowledge of statistics concepts, and scales measuring knowledge and attitudes regarding statistics and research. The questionnaire took approximately 10 minutes to complete. During the recruitment, students were notified that they were eligible to receive monetary incentives upon the completion of all sessions.

\subsection{Pariticipants.}

The first author used a three pronged approach to recruit potential participants. First, posters were developed and emailed to students on a BSW mass mailing list. Second, posters were placed on notice boards in university library and academic buildings. Third, faculty, staff and students were asked to refer prospective students to this project. A formal information session was hosted in the School of Social Work building to meet students and answer their questions. Initially, a total of eleven students showed interest in the project but by the beginning of the first class only seven students attended the first class. Of those seven, all completed the entire research project. 


\subsection{Program Discription}

The core component of this pilot project was the three-week intensive training program during the university's summer semester. During this period, BSW students attended five 2-hour sessions and learned various data management skills. The teaching plan for the five sessions included data entry in SPSS, recoding variables, sample univariate analysis, sample bivariate analysis, and graphic presentation of data.

The project was implemented via two mentoring relationships- faculty advising of doctoral students, and doctoral students teaching undergraduates. The first author designed the teaching plan, lecture slides, and lab assignments for two doctoral students. Doctoral students met directly with the undergraduate learners, teaching and mentoring them in the social work computer lab. The statistical software used in class was SPSS.

\subsection{The Role of Doctoral Students}

Two social work doctoral candidates (one male and one female) participated in this project as teaching assistants. Both had completed their doctoral level coursework and were beginning their dissertation proposal writing. Regardless of their level of experience with SPSS data management and analysis skills, the faculty introduced them to the teaching lessons to ensure that they were fully prepared to teach independently. Regularly scheduled meetings kept the faculty advisor apprised of the BSW students' progress. In addition to regular teaching sessions, doctoral students were responsible for grading in-class lab assignments and answering the students' emails and inquiries. Due to a small number of participants, one doctoral student taught three undergraduates and the other taught four. Upon completion, the mentors were compensated with stipends.

\subsection{The Activities of Undergraduate Mentees}

All seven undergraduates completed the five training sessions. Attendance was monitored by their sign-in and sign-out times. After the instructor finished the didactic lectures and explained the in-class data analysis exercises, students began to work on their assignments, receiving individualized assistance. At the end of each session, students submitted their assignments via email attachments. After fulfilling all requirements at the end of the five weeks, students earned a monetary reward and were administered post-intervention surveys to assess their attitudes toward research and skills. Comparing the pre- and post-test scores evaluated the program effectiveness.

\subsection{Measures}

Demographic information collected included age, gender, race/ethnicity, years in college, and number of math or statistics completed. The SATS-36 scale was utilized to assess the participants' attitudes toward research. Their pre-intervention proficiency with twelve statistical concepts was measured using binary variables with 1 indicating "knowing that particular statistical concept", and 0 representing "not knowing". The concepts included: access to SPSS; entering data; continuous variable; categorical variable; nominal variable; ordinal variable; calculating a sample mean; correlation coefficient; making figures in Excel; data entry in Excel; calculating a sample mean using Excel; and typing equations in Word.

The SATS-36 is a 36-item scale that measures six domains of the student's knowledge and attitude toward statistics. The six attitude components include: affect (6 items); cognitive competence (6 items); value (9 items); difficulty (7 items); interest (4 items), and effort (4 items). Each of the subscale items was measured with a 7-point Likert scale: $1=$ strongly disagree, $4=$ neutral and $7=$ strongly agree. Higher scores corresponded to more positive attitudes. Due to the small sample size the internal consistency reliability by Cronbach's alpha was not measurable. However, the SATS-36 has been proved to be a valid and reliable instrument by researchers (Carnell, 2008; VanHoof, Kuppens, Sotos, Verschaffel, \& Onghena, 2011). The six sub-scales used in this study to measure the students' attitudes about the statistics course are explained below.

Affect. This subscale includes six items measuring students' feelings about statistics. Examples are "I will like statistics", "I will feel insecure when I have to do statistics problems", "I will get frustrated going over statistics tests in class", "I will be under stress during statistics class", "I will enjoy taking statistics courses", and "I am scared by statistics."

Cognitive Competence. This concept contains six items and measures students' attitudes about their intellectual knowledge and skills when applied to statistics. Examples of items for this scale are "I will have trouble understanding statistics because of how I think", "I will have no idea of what's going on in this statistics course", "I will make a lot of math errors in statistics", "I can learn statistics", "I will understand statistics equations", and "I will find it difficult to understand statistical concepts."

Value. This subscale contains nine items and measures students' attitudes about the usefulness, relevance, and worth of statistics in personal and professional life. Those items are presented as the following. 1. "Statistics is 
worthless." 2. "Statistics should be a required part of my professional training." 3. "Statistics skills will make me more employable." 4. "Statistics is not useful to the typical professional." 5. "Statistics thinking is not applicable in my life outside my job." 6. "I use statistics in my everyday life." 7. "Statistics conclusions are rarely presented in everyday life." 8. "I will have no application for statistics in my profession." 9. "Statistics is irrelevant in my life."

Difficulty. This subscale includes seven items and measures students' attitudes about the difficulty of statistics as a subject. Examples of items are "statistic formulas are easy to understand", "statistics is a complicated subject", "statistics is a subject quickly learned by most people", "learning statistics requires a great deal of discipline", "statistics involves massive computations," "statistics is highly technical", and "most people have to learn a new way of thinking to do statistics."

Interest. This subscale contains four items and assesses students' level of individual interest in statistics. Examples of items are "I am interested in being able to communicate statistical information to others", "I am interested in using statistics", "I am interested in understanding statistical information", and "I am interested in learning statistics."

Effort. The last subscale contains four items and assesses the amount of work the student will expend to learn statistics. Examples of items are "I plan to complete all of my statistics assignments", "I plan to work hard in my statistics course", "I plan to study hard for every statistics test", and "I plan to attend every statistics class session."

\subsection{Data Analysis}

Data were entered and checked for missing data. The latest version of SPSS 22.0 was used for analysis of variables. Mean values of the demographic variables and the twelve indicators of knowledge of statistical concepts are reported. For the six subscales, the mean, standard deviation, minimum and maximum are reported. In addition, a paired-samples t-test was completed for each subscale to determine whether measured changes from pretest to posttest were statistically significant at the 0.05 alpha level $(\alpha=.05)$.

\section{Results}

This convenience sample consisted of one male and six female African American students at a HBCU university. The students came from a wide range of majors: predominantly social work and one each from math, sociology, psychology, and business. Ages ranged from 20 to 60 years, with three students in their 20 s and one student each in their $30 \mathrm{~s}, 40 \mathrm{~s}, 50 \mathrm{~s}$, and $60 \mathrm{~s}$. The mean age was 38 with the youngest 21 years and the oldest 65 . One student was sophomore, three were junior, and the other three were seniors, respectively. The combination of traditional and non-traditional students produced distinct learning outcomes. Younger students completed the in-class exercises at a faster pace than the older ones. The six students with a non-math major had taken only two college-level math and/or statistics courses, which reflected the standard level of math requirements at the college level.

As shown below in Table 1, this program significantly improved students' knowledge of statistical concepts. Prior to the training, only $28.6 \%$ of the respondents had some understanding of a correlation coefficient; $42.9 \%$ had knowledge about continuous variables, nominal variables, ordinal variables, and how to calculate a sample mean in Excel; $57.1 \%$ understood sample mean and creating equations in Word; 71.4\% knew SPSS software, how to enter data in SPSS, categorical variables, creating figures in Excel; and $85.7 \%$ could enter data in Excel. By the end of the five training sessions, all participants had become familiar with all twelve statistical concepts. Completion rate was $100 \%$.

Table 1. Sample mean for twelve binary indicators of knowledge of statistical concepts

\begin{tabular}{lll}
\hline Variables & Pretest (\%) & Posttest (\%) \\
\hline Whether used SPSS before? & 71.4 & 100 \\
Whether know data entry in SPSS? & 71.4 & 100 \\
Whether know continuous variable? & 42.9 & 100 \\
Whether know categorical variable? & 71.4 & 100 \\
Whether know nominal variable? & 42.9 & 100 \\
Whether know ordinal variable? & 42.9 & 100 \\
Whether know sample mean? & 57.1 & 100 \\
Whether know correlation coefficients? & 28.6 & 100 \\
Whether know making figure in Excel? & 71.4 & 100 \\
Whether know entering data in Excel? & 85.7 & 100 \\
Whether know calculating sample mean in Excel? & 42.9 & 100 \\
Whether know typing equations in Word? & 57.1 & 100 \\
\hline
\end{tabular}


For each SATS-36 subscale, the aggregate score was obtained by summing across all items. For example, the subscale "affect" contained six items and the aggregate score was the sum of the six scores. A mean was then calculated by dividing the total aggregate score by the number of subscale items. Higher scores corresponded to more positive attitude in that particular subscale. As seen in Table 2 below, the pretest and posttest scores for the six subscales were very different. There was an increase in pretest to posttest mean scores for $66.7 \%$ of the subscales. These included affect $(4.0+1.6$ to $5.4+1.2)$, cognitive competence $(4.7+1.5$ to $5.8+0.8)$, value $(3.1$ +0.3 to $3.3+0.5)$, and effort $(5.6+2.3$ to $6.3+0.8)$. Upon completion of the pilot training program, undergraduates had gained more positive feelings about statistics, increased their attitudes about their intellectual knowledge and skills when applied to statistics, increased their attitudes about the usefulness, relevance, and worth of statistics in their personal and professional lives, and planned to make greater efforts in learning statistics.

Table 2. Descriptive statistics for six subscales

\begin{tabular}{|c|c|c|c|c|c|c|c|c|}
\hline \multirow[t]{2}{*}{ \# Subscales } & \multicolumn{4}{|c|}{ Pretest Score } & \multicolumn{4}{|c|}{ Posttest Score } \\
\hline & Mean & SD & Min & Max & Mean & SD & Min & Max \\
\hline Affect & 4.0 & 1.6 & 1.5 & 7 & 5.4 & 1.2 & 3.7 & 7 \\
\hline Cognitive & 4.7 & 1.5 & 2 & 7 & 5.8 & 0.8 & 4.33 & 7 \\
\hline \multicolumn{9}{|l|}{ Competence } \\
\hline Value & 3.1 & 0.3 & 2.6 & 3.3 & 3.3 & 0.5 & 2.6 & 4 \\
\hline Difficulty & 4.4 & 0.7 & 3.5 & 5.7 & 3.9 & 0.8 & 3.1 & 5 \\
\hline Interest & 5.2 & 1.5 & 2.5 & 7 & 4.8 & 1.4 & 3 & 7 \\
\hline Effort & 5.6 & 2.3 & 1 & 7 & 6.3 & 0.8 & 5 & 7 \\
\hline
\end{tabular}

Paired-samples t-tests were performed to test whether the mean differences from the pretest to posttest were statistically significant. As shown in Table 3, significantly different mean scores were found in two domains, affect (mean difference $=-1.31 ; t=-3.19 ; p=.019$ ) and cognitive competence (mean difference $=-1.10 ; t=$ $-3.71 ; p=.010)$. The mean difference indicated the amount of movement on the Likert scale for the domain measured. By the end of the project students displayed significantly more positive feelings and attitudes toward statistics. The remaining four domains, value, difficulty, interest, and effort, showed no statistical significance in their mean difference, which may have been because of the small sample size.

Table 3. Paired-samples t-test of six subscales of SATS-36

\begin{tabular}{lllllll}
\hline Paired samples & Mean & Mean difference & Std. dev. & t & df & Sig. \\
\hline Affect (pre) & 4.04 & -1.31 & 1.08 & -3.19 & 6 & $.019^{*}$ \\
Affect (post) & 5.35 & & & & & $.010^{*}$ \\
Cognitive (pre) & 4.69 & -1.10 & .78 & -3.71 & 6 & .070 \\
Cognitive (post) & 5.78 & & & & & .196 \\
Value (pre ) & 3.08 & -.25 & .31 & -2.20 & 6 & .236 \\
Value (post) & 3.33 & & & & & \\
Difficult (pre) & 4.43 & .57 & 1.04 & & 6 & .532 \\
Difficult (post) & 3.86 & & & & & \\
Interest (pre) & 5.14 & .393 & .789 & & 6 & \\
Interest (post) & 4.75 & & & & & \\
Effort (pre) & 5.61 & -.643 & 2.565 & & & \\
Effort (post) & 6.25 & & & & &
\end{tabular}

Note. ${ }^{\mathrm{p}}<.05 ; * * \mathrm{p}<.01$

\section{Conclusion and Discussion}

These findings indicate that participating in a faculty led, peer assisted tutoring non-credited course was effective in improving undergraduate students' attitudes and knowledge about research and statistics. These data support Ginty \& Harding's (2014) findings that an important benefit to the peer mentoring was related to an increased understanding of the subject matter. All participants became familiar with the twelve statistical terms, whereas none of them had fully understood the twelve terms prior to the statistics camp. Two of the six domains that evaluated students' attitudes toward statistics yielded significant changes in mean scores from the pretest to posttest. The undergraduate learners gained more positive affect related to statistics and an increase in their positive attitude about their intellectual knowledge and statistical skills. Even though the remaining four domains did not yield significantly different pre- to posttest mean scores, $50 \%$ of the participants had higher posttest scores 
in their attitudes about the usefulness, relevance, and worth of statistics in their personal and professional life, and their plans to make more efforts to learn statistics.

While this pilot program produced significant improvements in the students' attitudes toward research, there were limitations to the study. First, the small sample size prevented generalization of these results to a wider student population. Because recruitment did not occur when most students were on campus, ability to recruit was limited. In the future, establishing this statistics camp as a regular non-credited class would allow students to plan ahead. Larger enrollment would certainly consolidate the program effectiveness. Furthermore, given the small sample size it was not possible to conduct more sophisticated multivariate analysis to identify predictors and their impact on learning outcomes. Thus, it is unknown whether other confounding factors played a role with the observed changes.

Second, these data do not distinguish between treatment and comparison groups. Initially, a comparison of outcomes between social work students versus non-social work students was planned so a number of determinant factors for changes could be teased apart. For instance, it was unknown whether course instructors were the cause of the change. Because both instructors were social work doctoral candidates, they primarily employed social work examples to demonstrate points, even though the group of students was multidisciplinary. Due to small sample size it was not possible to analyze whether this discipline-oriented instruction impacted the students' learning outcomes.

Third, the monetary incentive may influence the completion of the program. It becomes increasingly popular among researchers that monetary incentives are used to help motivate program participant. There is ongoing discussion asking whether, and under what conditions, the use of monetary incentives to persuade participation might be coercive (Singer \& Couper, 2008). Based on informal communications with undergraduates, the faculty advisor learned that the monetary reward did play an important role to retain participants. Despite strong desires to learn, all participants indicated that transportation costs prevented them from access to additional learning opportunities offered by the university. This reward helped them overcome the major obstacle.

Fourth, we did not differentiate the number of math courses versus statistics courses in the survey questionnaire. Evidently, math and statistics courses were not substitutes in the undergraduate curriculum. The future study will certainly address this issue, and examine the separate effects of taking math versus statistics courses.

The research findings are very promising and encourage further research in the area of peer assisted teaching and learning of research classes. Results of this pilot research make two suggestions. One the one hand, undergraduate students can benefit from a similar camp designed to improve their understanding of statistics and their attitude toward research. Students' overall enthusiasm for this camp training was incredible given the amount of work it required during the summer holiday. All the participants communicated with the faculty advisor that they made the right decisions to participate this camp which increased their understanding of research in an enjoyable and encouraging learning environment. Therefore, it is imperative that instructors take the lead in improving their pedagogy and creating cooperative learning environments that are open to students' concerns and worries.

On the other hand, doctoral students can benefit by reinforcing their statistical knowledge and gaining valuable classroom leadership skills which will help prepare them for a future academic career. One of the advantages to peer-assisted learning is that it can differ from a tutoring program because peers are students in the same educational program as the person receiving help. Because this is cross-peer relationship, the recipient may be encouraged that the mentor also is learning. Even though the mentor is becoming more proficient in the material he or she is teaching, Weyrich, Celeci, Schrauth, Moltner, Lammerding-Koppel, and Nikendei (2009) found that the students whose mentors were students demonstrated as much success as their counterparts whose mentors were faculty.

\section{Implications}

This statistics camp received unanimous support from participating undergraduates and doctoral candidates. They supported formalizing this project into a regularly scheduled non-credited class which would be integrated into the learning curricula during each semester in the academic year. The establishment of a mentor-mentee statistics camp would be particularly helpful at an HBCU because the proportion of African American and Hispanic students who enter STEM fields is very low (Schwartz, 2012). Schwartz argued that while increased involvement from undergraduate research faculty to support students of color is critical it often burdens the HBCU faculty who are often struggling to provide research training with inadequate resources. Establishing a peer assisted statistics camp allows the instructor to train a small number of doctoral students, who in turn will train a large number of undergraduate students. Thus the difference between the peer-assisted model and faculty instruction may be the reduction in levels of burden among the faculty and anxiety among the students when interacting with instructors. 
Tutoring usually offered by the university differs from peer-assisted learning because tutors are often paid instructors and function as "mini-faculty" (Fougner, 2012) while doctoral students who function as peer mentors can create rapport based on modeling "I am learning too" and empathy "I know how you feel." This position differs from a common stance of new teachers which is "I'm the authority, don't challenge me" (Oktay, Jacobson, $\&$ Fisher, 2013). The success of this pilot project indicated that peer mentors could train undergraduate students in a STEM research course and suggested several directions for improvement of undergraduate students' research capacity in future research.

First, special non-credited research training could be integrated into the curriculum as part of a Student Success Center program. Campus wide resource integration could greatly benefit undergraduates. Student Success Centers often offer specialized advising to help students achieve their academic success such as a non-credited Study Skill Seminar to promote positive study habits. Students who enroll in each seminar meet weekly to discuss general topics such as identifying individual learning styles, test-taking techniques, stress management, note-taking styles, and other useful study skills. Establishing a statistics camp as a non-credited research seminar in a Student Success Center program may increase student retention in research methods classes. This is critical because research classes are mandatory for degree completion in the majority of discipline programs and professional schools. A non-credited seminar helps students learn information without worrying about passing grades. With better preparation and understanding of the material, students may be more likely to achieve success in the regular research class.

Second, specialized research training may increase retention and graduation rates. Results from this pilot indicate that students indicated that in regular classes, they often don't have time to digest the class material and relate the value of research to their personal and professional lives. Lectures and notes memorization reduce interaction with a faculty member and engagement with the subject. Enrolling in a non-credited class allows students to overcome their anxiety level about failing the research class. A statistics camp in the form of a non-credit course helps students relax, unwind, digest, improve their computer literacy and prepare for credit courses without feeling pressured about achieving a passing grade. Tinto (2006) found that earning failing grades is a major reason that contributes to a low graduation rate. Educators who view student attrition as the reflection of the student's individual attributes, skills, and motivation are less likely to improve their teaching methods (Stage \& Kinzie, 2009). This stance has been discredited because developing a non-credit statistics course focusing on collaboration and peer learning has been identified as improving grades (Goonatilake et al., 2010) and retention rates (Chesney, 2011).

Third, incorporating teaching assistantship opportunities into doctoral education will benefit both doctoral candidates and undergraduate students. Unlike their peers at a large, research-intensive Research I university, doctoral students at a small HBCU often do not have access to teaching assistantships that offer free tuition and stipends in exchange for teaching. Thus it is difficult to establish and maintain a doctoral program. Developing short-term teaching assistantship opportunities for PhD students provides practical, on-the-job skills, develops classroom leadership skills, and reinforces their research knowledge base. This project found that doctoral candidates indicated a strong desire to establish a statistics camp as an ongoing graduate teaching assistantship position for other students. With this invaluable teaching opportunity, they can reinforce concepts they had learned, refine their skill sets, and become familiar with challenges they will face before they begin actual academic jobs which will increase their preparation as future educators.

In summary, this peer assisted teaching model can play a significant role in helping undergraduate students increase their knowledge in research. The rewards for all stakeholders (undergraduates, doctoral students, and faculty) exceed expectations.

\section{Acknowledgments}

This study was supported by the University's Summer Research Grant. The content is solely the responsibility of the author and does not necessarily represent the official views of the university.

\section{References}

Adam, N., Zosky, D., \& Unrau, Y. (2004). Improving the research climiate in social work curricula. Journal of Teaching in Social Work, 24(3-4), 1-18. http://dx.doi.org/10.1300/J067v24n03_01

Appel, M., Kronberger, N., \& Aronson, J. (2011). Stereotype threat impairs ability building: Effects on test preparation among women in science and technology. European Journal of Social Psychology, 41, 904-913. https://doi.org/10.1002/ejsp.835 
Bolin, B. L., Lee, K. H., GlenMay, L. F., \& Yoon, D. P. (2012). Impact of research orientation on attitudes toward research of social work students. Journal of Social Work Education, 48(2), 23-243. https://doi.org/10.5175/JSWE.2012.200900120

Bybee, R. W. (2010). Advancing STEM education: A 2020 version. Technoogy and Engineering Teacher, September, 30-35.

Carnell, L. J. (2008). The effect of a student-designed data collection project on attitudes toward statistics. Journal of Statistics Education, 16(1), 1-15. https://doi.org/10.1080/10691898.2008.11889551

Chesney, T. D. (2011). Transforming science education through peer-led team learning. Association of American Colleges and Universities. Peer Review (Summer), 8-10.

Council on Social Work Education. (2012). Educational Policy and Accreditation Standards. Retrived from http://www.cswe.org/File.aspx?id=13780

Davis, S. (2003). Statistics anxiety among female African American graduate-level social work students. Journal of Teaching in Social Work, 23(3/4), 143-158. http://dx.doi.org/10.1300/J067v23n03_12

DiNoia, J., \& Tripodi, T. (2008). Single-case design for clinical social workers (2nd edition). Washington, D.C.: National Association of Social Workers Press.

Dulmas, C. N., \& Sowers, K. M. (2012). The prefession of social work: Guided by history, led by evidence. New Jersey: John Wiley and Sons.

Einbinder, S.D. (2014). Reducing research anxiety among MSW student. Journal of Teaching in Social Work, 34(2), 2-16. http://dx.doi.org/10.1080/08841233.2013.863263

Education Trust. (2010). Reports reveal colleges with the biggest, smallest gaps in minority graduation rates in the U.S.

Retrieved

from

https://edtrust.org/press_release/reports-reveal-colleges-with-the-biggest-smallest-gaps-in-minority-graduatio n-rates-in-the-u-s-2/

Faver, C. A., Fox, M. F., Hunter, M. S., \& Shannon, C. (1986). Research and practice: Orientations of social work educators. Social Work, 31, 282-286. https://doi.org/10.1093/sw/31.4.282

Fischer, J. (1973). Is casework effective? A review. Social Work, 18, 5-20. https://doi.org/10.1093/sw/18.1.5

Fougner, A. (2012). Exploring knowledge through peer tutoring in a transitional learning community: An alternative way of teaching counseling skills to students in social work education. Social Work Education, 31(3), 287-301. http://dx.doi.org/10.1080/02615479.2011.557431

Ginty, C., \& Harding, N. M. (2014). The first year experience of a peer assisted learning program in two institutions of technology in Ireland. Journal of Peer Learning, 7(5), 36-56.

Goonatilake, R., Chappa, E. E., Bachnak, R. A., \& San Miguel, M. (2010). An intensive mathematics enrichment workshop for incoming college students. Journal of Mathematics and Technology, 3, 5-10.

Green, R. G., Bretzin, A., Leininger, C., \& Stauffer, R. (2001). Research learning attributes of graduate students in social work, psychology, and business. Journal of Social Work Education, 37, 333-341.

Harder, J. (2010). Overcoming MSW students' reluctance to engage in research. Journal of Teaching in Social Work, 30, 195-209. http://dx.doi.org/10.1080/08841231003705404

Hudson, W. W. (1978a). First axioms of treatment. Social Work, January, 65-70.

Hudson, W. W. (1978b). Research training in professional social work education. Social Service Review, 52(1), 116-121. https://doi.org/10.1086/643592

Kirk, S. A., Osmalov, M. J., \& Fischer, J. (1976). Social workers' involvement in research. Social Work, March, 121-124. https://doi.org/10.1093/sw/21.2.121

Ladson-Billings, G., \& Tate, W. F. IV. (1995). Toward a Critical Race Theory of Education. Teachers College Record, 97(1), 48-68.

Maschi, T., Wells, M., Slater, G. Y., MacMillan, T., \& Ristow, J. (2013). Social work students' research-related anxiety and self-efficacy: Research instructors' perceptions and teaching innovations. Social Work Education: The International Journal, 32(6), 800-817. http://dx.doi.org/10.1080/02615479.2012.695343

National Association of Social Workers. (2012). Bylaws of the National Association of Social Workers. Retrieved from http://www.socialworkers.org/assets/secured/documents/chapters/NASW-Bylaws.pdf 
Oktay, J. S., Jacobson, J. M., \& Fisher, E. (2013). Learning through experience: The transition from doctoral student to social work educator. Journal of Social Work Education, 49, 207-221.

Onwuegbuzie, A. J. (1999). Statistics anxiety among African American graduate students: An effective filter. Journal of Black Psychology, 25(2), 189-209. https://doi.org/10.1177/0095798499025002004

Pan, W., \& Tang. M. (2005). Students' perceptions on factors of statistics anxiety and instructional strategies. Journal of Instructional Psychology, 32(3), 205-214.

Peterson, S. M., Bacon, S. I., Phillips, A., \& Machunda, Z. (2011). Teaching evidence-based practice at the BSW level: An effective capstone project. Journal of Sodcial Work Education, 47(3), 509-524. https://doi.org/10.5175/JSWE.2011.200900129

Piotrowski, C., \& Hemasinha, R. (2012). Career aspirations of undergraduate mathematics majors: An exploratory study. College Student Journal, 46(1), 46-50.

Royse, D., \& Rompf, E. L. (1992). Math anxiety: A comparison of social work and non-social work students. Journal of Social Work Education, 28, 270-277.

Schau, C. (2003). Students' attitudes: The other important outcome in statistics education. 2003 ASA Proceedings: Papers presented at the American Statistical Asocation Joints Statistical Meetings. Alexandria, VA: American Statistical Association, Section on Statistical Education, [CD-ROM] pp. 3673-3681.

Schwartz, J. (2012). Facutly as undergraduate research mentors for students of color: Taking into account the costs. Science Education, 96, 527-542. https://doi.org/10.1002/sce.21004

Singer, E., \& Couper, M. P. (2008). Do incentives exert undue influence on survey participation? Experimental evidence. Journal of Empirical Research Human Research Ethics, 3(3), 49-56. https://doi.org/10.1525/jer.2008.3.3.49

Stage, F. K., \& Kinzie, J. (2009). Reform in undergraduate science, technology, engineering, and mathematics: The classroom context. Journal of General Education, 58(2), 85-105. https://doi.org/10.1353/jge.0.0038

Talley, C. P., \& Scherer, S. (2013). The enhance flipped classroom: Increasing academic performance with student-recorded lectures and practices testing in a "Flipped" STEM course. The Journal of Negro Education, 82(3), 339-347. https://doi.org/10.7709/jnegroeducation.82.3.0339

Tinto, V. (2006). Research and practice of student retention: What next? Journal of College Student Retention, 8(1), 1-19. https://doi.org/10.2190/4YNU-4TMB-22DJ-AN4W

Toldson, I. A. (2013). Historically Black Colleges and Universities can promote leadership and excellence in STEM (Editor's Commentary). The Journal of Negro Education, 82(4), 359-367. https://doi.org/10.7709/jnegroeducation.82.4.0359

Tripodi, T. (1994). A primer on single-subject design for clinical social workers (1st edition). Washington, D.C.: National Association of Social Worker Press.

Unrau, Y. A., \& Beck, A. R. (2004). Increasing research self-efficacy among students in professional academic $\begin{array}{llll}\text { programs. } \quad \text { Innovative } & \text { Higher 28(3), } & \text { 187-204. }\end{array}$ https://doi.org/10.1023/B:IHIE.0000015107.51904.95

VanHoof, S., Kuppens, S., Sotos, A. E. C., Verschaffel, L., \& Onghena, P. (2011). Measuring statistics attitudes: Structure of the Survey of Attitudes toward Statistics (SATS-36). Statistics Education Research Journal, 10(1), 35-51.

Weyrich, P., Celebi, N., Schrauth, M., Moltner, A., Lammerding-Koppel, M., \& Nikendei, C. (2009). Peer-assisted versus faculty staff-led skills laboratory training: A randomized controlled trial. Medical Education, 43, 113-120. https://doi.org/10.1111/j.1365-2923.2008.03252.x

\section{Copyrights}

Copyright for this article is retained by the author(s), with first publication rights granted to the journal.

This is an open-access article distributed under the terms and conditions of the Creative Commons Attribution license (http://creativecommons.org/licenses/by/4.0/). 